\title{
IMPLEMENTASI SISTEM INFERENSI FUZZY PADA PENGAMBILAN KEPUTUSAN PENENTUAN KUALITAS AIR PDAM
}

\author{
S. Oktavia1 ${ }^{1}$, S. Musdalifah ${ }^{2}$, dan D. Lusiyanti ${ }^{3}$ \\ 1,2,3Program Studi Matematika Jurusan Matematika FMIPA Universitas Tadulako \\ Jalan Soekarno-Hatta Km. 09 Tondo, Palu 94118, Indonesia. \\ 1susantioktavia17@gmail.com, ${ }^{2}$ selvymusdalifah@yahoo.com, ${ }^{3}$ desylusiyanti@gmail.com
}

\begin{abstract}
Water is one of the most important natural resources for all living things. For humans, water is used for bathing, washing and drinking so that the quality needs to be considered. Water quality is a major factor to determine the feasibility of water to be used. The purpose of this research is to implement Fuzzy inference system on decision making to determine water quality of PDAM. Mamdani method is used as a fuzzy inference systems and GUIDE MATLAB is used as a program that can facilitate the users. Input of the system in the form of values of water quality parameters test results the parameters are Color, Turbidity, Total Dissolved Solid (TDS), Nitrite, Nitrate, Coliform, e-coli, and $\mathrm{pH}$. System works well in determining the quality of water, it can be evidenced by the level of accuracy of $94,44 \%$ of the 72 data used in Laboratory Uwe Lino Donggala District Laboratory and Palu District PDAM Laboratory.
\end{abstract}

Keywords : Fuzzy Inference System, Mamdani Method, Water Quality.

\section{ABSTRAK}

Air adalah salah satu sumber daya alam yang sangat dibutuhkan bagi seluruh makhluk hidup. Bagi manusia, air digunakan untuk mandi, cuci dan diminum sehingga kualitasnya perlu diperhatikan. Kualitas air adalah faktor utama untuk mengetahui kelayakan air yang akan digunakan. Tujuan dari penelitian ini adalah untuk mengimplementasikan sistem inferensi Fuzzy pada pengambilan keputusan penentuan kualitas air PDAM. Metode Mamdani digunakan sebagai sistem inferensi fuzzy serta guide matlab digunakan sebagai program yang dapat memudahkan pengguna. Inputan sistem berupa nilai-nilai hasil uji parameter kualitas air yaitu Warna, Kekeruhan, Total zat padat terlarut (TDS), Nitrit, Nitrat, Coliform, e-coli, dan pH. Sistem ini bekerja dengan baik dalam menentukan kualitas air. Hal tersebut dapat dibuktikan dengan tingkat akurasi sebesar $94,44 \%$ dari 72 data yang bersumber dari Laboratorium PDAM Uwe Lino Kabupaten Donggala dan Laboratorium PDAM Kota Palu.

Kata Kunci : : Sistem Inferensi Fuzzy, Metode Mamdani, Kualitas Air 


\section{PENDAHULUAN}

\subsection{Latar Belakang}

Air adalah salah satu sumber daya alam yang penting bagi kehidupan makhluk hidup, dimana hampir setiap makhluk hidup membutuhkan air untuk keberlangsungan hidupnya. Pentingnya air untuk kehidupan maka kuantitasnya perlu di perhatikan. Namun, mengingat air merupakan salah satu media penularan berbagai macam penyakit maka air bukan hanya harus terpenuhi secara kuantitas melainkan harus terjamin pula kualitasnya[1].

Salah satu pihak yang bertanggung jawab dalam menjaga kualitas air untuk pelanggannya adalah PDAM. Perusahaan Daerah Air Minum ini atau yang lebih di kenal dengan PDAM adalah perusahan pemerintah yang memiliki kewenangan dalam hal proses pengolahan dan penjernihan air. Untuk pemantauan secara berkala atas kualitas air yang dialirkan oleh PDAM maka perlu adanya suatu sistem bagi pihak PDAM sendiri maupun bagi pelanggannya. Dengan memanfaatkan hasil uji laboratorium dari parameter kualitas air sebagai inputannya, maka didesain suatu sistem dengan menggunakan logika fuzzy. Logika fuzzy dipilih karena sangat fleksibel artinya mampu merepresentasikan ketidakpastian yang menyertai permasalahan seperti airnya "sedikit" keruh dan sebagainya. Selain itu, dapat mengaplikasikan pengalaman-pengalaman para pakar secara langsung tanpa harus melalui proses pelatihan sehingga memudahkan orang awam dalam menentukan tingkat kualitas air.

\subsection{Rumusan Masalah}

Adapun rumusan masalah dari penelitian ini adalah bagaimana implementasi sistem inferensi fuzzy mamdani pada pengambilan keputusan penentuan kualitas air PDAM ?

\subsection{Batasan Masalah}

Batasan masalah dalam penelitian ini adalah :

1. Sistem Inferensi Fuzzy yang digunakan adalah metode Mamdani.

2. Parameter yang digunakan adalah parameter hasil uji laboratorium yaitu warna, kekeruhan, Total Dissolved Solid (TDS), pH, nitrit, nitrat, coliform, dan e-coli yang bersumber dari data PDAM Kota Palu dan PDAM Uwe Lino Kabupaten Donggala sedangkan parameter kualitas air yang lain diabaikan.

3. Data yang digunakan adalah data hasil Uji Laboratorium dari parameter kualitas air pada bulan Mei tahun 2017. 


\section{METODE PENELITIAN}

Penelitian dilakukan sesuai prosedur dibawah ini :

1. Mulai

2. Identifikasi Masalah

3. Studi Literatur

4. Pengumpulan data

5. Pembentukan semesta pembicaraan

6. Pembentukan himpunan fuzzy dan domain fuzzy

7. Penentuan representasi kurva dari setiap variabel

8. Pembentukan evaluasi aturan fuzzy (rule)

9. Penentuan nilai keanggotaan dari setiap variabel

10. Penentuan nilai keanggotaan dari setiap rule

11. Penentuan derajat kebenaran dari setiap himpunan output fuzzy

12. Penentuan momen dan luas dari daerah output

13. Hasil

14. Kesimpulan

15. Selesai

\section{HASIL DAN PEMBAHASAN}

\subsection{Semesta Pembicaraan}

Penentuan semesta pembicaraan diperoleh dari jurnal, artikel yang dikutip baik dari ebook, dan sebagainya. Semesta pembicaraan untuk setiap variabel yaitu rentang dari nilai terkecil ke nilai terbesar. Semesta pembicaraannya adalah sebagai berikut :

Tabel 1 : Semesta Pembicaraan

\begin{tabular}{|c|c|c|}
\hline \multirow{4}{*}{ Fungsi } & Nama Variabel & Semesta Pembicaraan \\
\hline \multirow{4}{*}{ Input } & Warna & {$[0-121]$} \\
\cline { 2 - 3 } & Kekeruhan & {$[0-50]$} \\
\cline { 2 - 3 } & TDS & {$[0-1500]$} \\
\cline { 2 - 3 } & Nitrit & {$[0-2]$} \\
\cline { 2 - 3 } & Nitrat & {$[0-20]$} \\
\cline { 2 - 3 } & Coliform & {$[0-50]$} \\
\cline { 2 - 3 } & e-coli & {$[0-50]$} \\
\hline \multirow{2}{*}{ Output } & pH & {$[0-14]$} \\
\hline
\end{tabular}




\subsection{Himpunan Fuzzy}

Pada tahap ini, dibentuk himpunan fuzzy dan domain dari semesta pembicaraan. Himpunan fuzzy adalah pemberian nama untuk nilai-nilai yang termuat dalam domain fuzzy disetiap variabel. Model 9 variabel fuzzy yang dibangun dalam penelitian ini, yaitu :

1. Warna : Terdiri dari 3 himpunan fuzzy yaitu bening, agak berwarna dan cukup berwarna.

2. Kekeruhan : Terdiri dari 3 himpunan fuzzy yaitu sedikit, sedang dan banyak

3. TDS : Terdiri dari 3 himpunan fuzzy yaitu baik, sedang dan buruk

4. Nitrit : Terdiri dari 3 himpunan fuzzy yaitu rendah, sedang dan tinggi

5. Nitrat : Terdiri dari 3 himpunan fuzzy yaitu rendah, sedang dan tinggi

6. Coliform : Terdiri dari 3 himpunan fuzzy yaitu tidak ada, sedikit, dan banyak

7. E-Coli : Terdiri dari 3 himpunan fuzzy yaitu tidak ada, sedikit, dan banyak

8. $\mathrm{pH} \quad$ : Terdiri dari 3 himpunan fuzzy yaitu asam, netral dan basa

9. Hasil : Terdiri dari 3 himpunan fuzzy yaitu air dapat diminum, air bersih dan air tercemar

\subsection{Variabel Warna}

Untuk merepresentasikan variabel warna digunakan kurva linear turun untuk himpunan fuzzy sangat jernih, kurva segitiga untuk himpunan fuzzy jernih, dan kurva linear naik untuk himpunan fuzzy sedang. Adapun grafik Variabel Input Warna sebagai berikut :

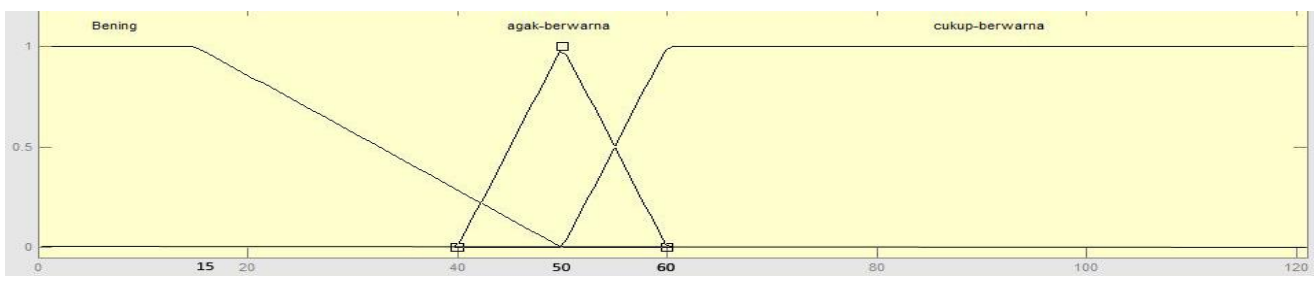

Gambar 1 : Grafik Variabel Input Warna

\subsection{Variabel Kekeruhan}

Untuk merepresentasikan variabel kekeruhan digunakan kurva linear turun untuk himpunan fuzzy sedikit, dan kurva linear naik untuk himpunan fuzzy sedang. Adapun grafik Variabel Input Kekeruhan sebagai berikut :

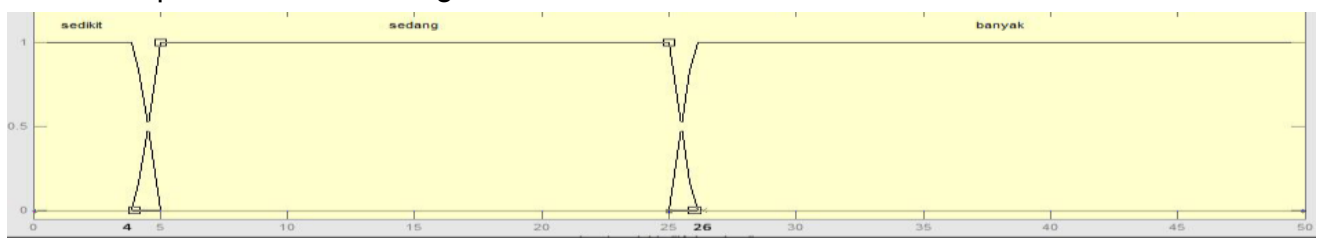

Gambar 2 : Grafik Variabel Input Kekeruhan 


\subsection{Variabel TDS (Total Dissolved Solids)}

Untuk merepresentasikan variabel TDS digunakan kurva linear turun untuk himpunan fuzzy baik, kurva segitiga untuk himpunan fuzzy sedang, dan kurva linear naik untuk himpunan fuzzy buruk. Adapun grafik Variabel Input TDS sebagai berikut :

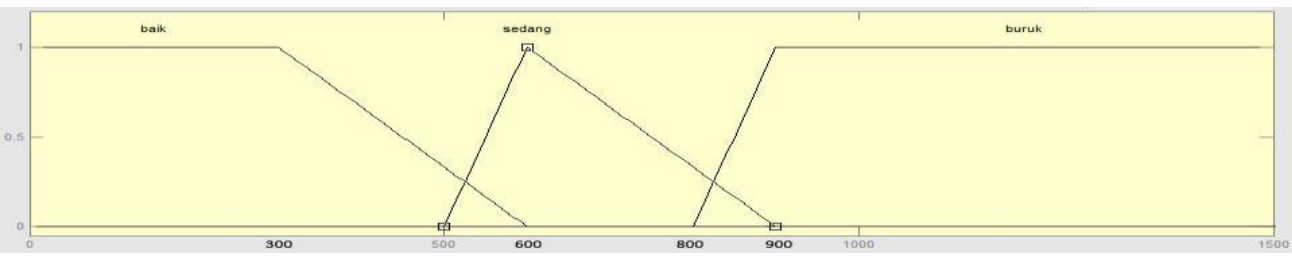

Gambar 3 : Grafik Variabel Input TDS (Total Dissolved Solids)

\subsection{Variabel Nitrit}

Untuk merepresentasikan variabel nitrit digunakan representasi kurva linear turun untuk himpunan fuzzy rendah, kurva segitiga untuk himpunan fuzzy sedang, dan representasi kurva linear naik untuk himpunan fuzzy tinggi. Adapun grafik Variabel Input Nitrit sebagai berikut :

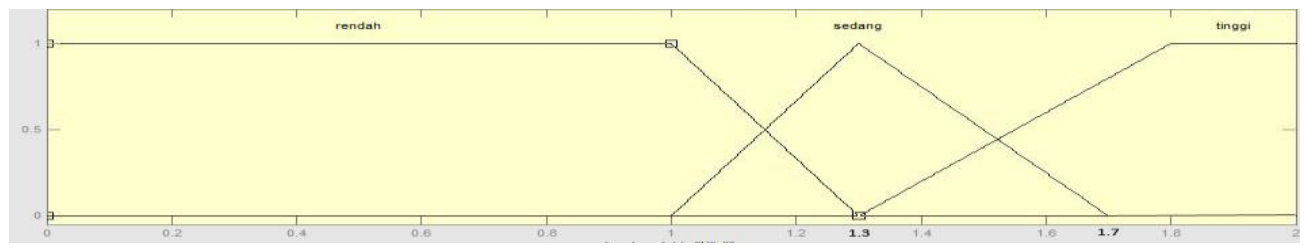

Gambar 4 : Grafik Variabel Input Nitrit

\subsection{Variabel Nitrat}

Untuk merepresentasikan variabel nitrat digunakan representasi kurva linear turun untuk himpunan fuzzy rendah, kurva segitiga untuk himpunan fuzzy sedang, dan representasi kurva linear naik untuk himpunan fuzzy tinggi. Adapun grafik Variabel Nitrat sebagai berikut :

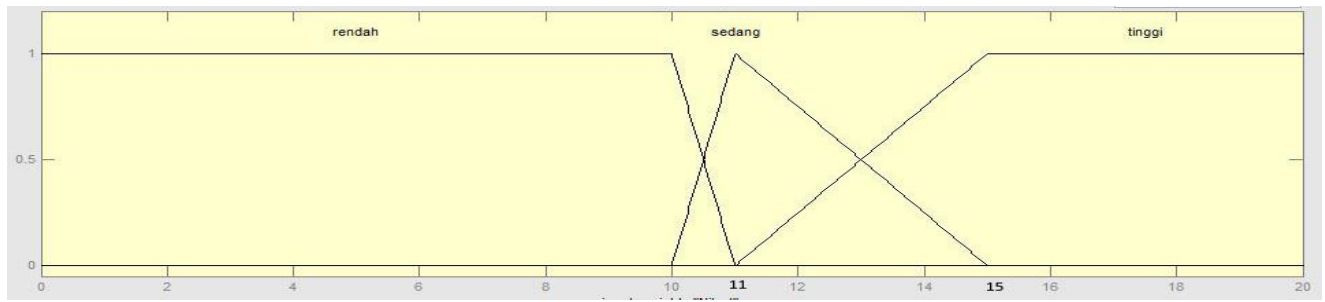

Gambar 5 : Grafik Variabel Input Nitrat 


\subsection{Variabel Coliform}

Untuk merepresentasikan variabel coliform digunakan representasi kurva linear turun untuk himpunan fuzzy tidak ada, kurva trapesium untuk himpunan fuzzy sedikit, dan representasi kurva linear naik untuk himpunan fuzzy banyak. Adapun grafik Variabel Coliform sebagai berikut :

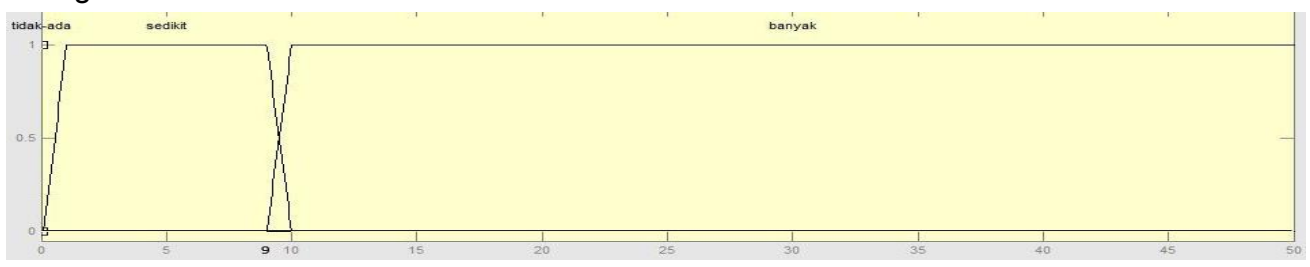

\section{Gambar 6 : Grafik Variabel Input Coliform}

\subsection{Variabel E-Coli}

Untuk merepresentasikan variabel e-coli digunakan representasi kurva linear turun untuk himpunan fuzzy tidak ada, kurva trapesium untuk himpunan fuzzy sedikit, dan representasi kurva linear naik untuk himpunan fuzzy banyak. Adapun grafik Variabel e-coli

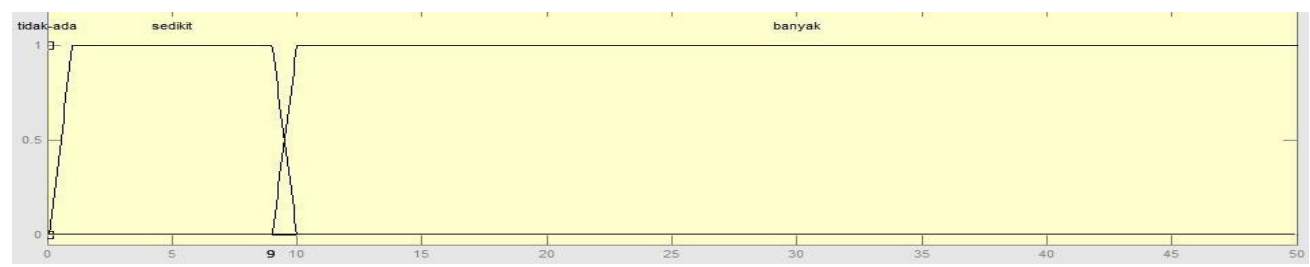

sebagai berikut :

Gambar 7 : Grafik Variabel Input E-Coli

\subsection{Variabel $\mathrm{pH}$}

Untuk merepresentasikan variabel $\mathrm{pH}$ digunakan representasi kurva linear turun untuk himpunan fuzzy asam, kurva segitiga untuk himpunan fuzzy netral dan representasi kurva linear naik untuk himpunan fuzzy basa. Adapun grafik Variabel Input $\mathrm{pH}$ sebagai berikut :

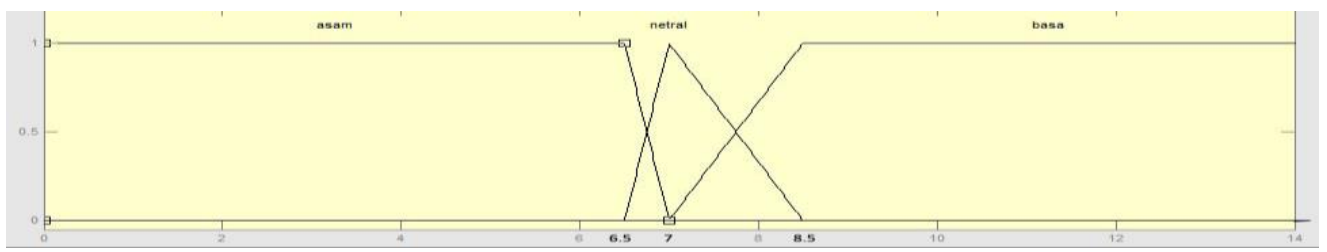

Gambar 8 : Grafik Variabel Input pH 


\subsection{Variabel Hasil}

Untuk merepresentasikan variabel hasil digunakan representasi kurva linear turun untuk himpunan fuzzy air dapat diminum, kurva trapesium untuk himpunan fuzzy air bersih, dan representasi kurva linear naik untuk himpunan fuzzy air tercemar. Fungsi keanggotaan digunakan untuk menentukan nilai keanggotaan. Adapun grafik Variabel Output Hasil sebagai berikut :

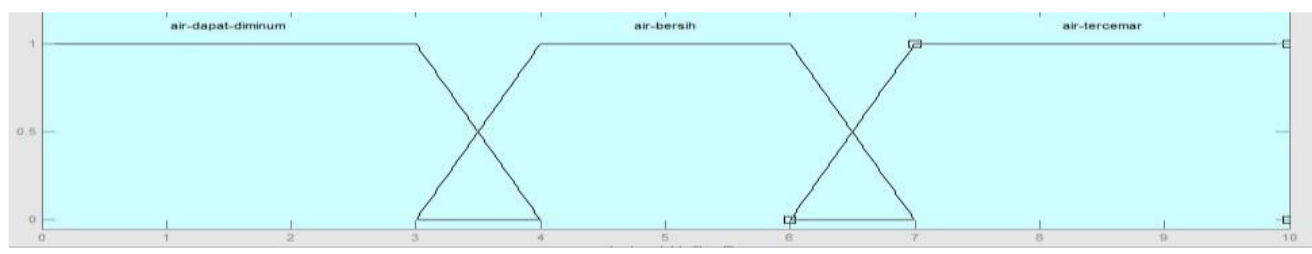

Gambar 9 : Grafik Variabel Output Hasil

\subsection{Rule Logika Fuzzy}

Setelah penentuan fungsi keanggotaan variabel maka dilakukan pembentukan aturanaturan logika fuzzy (rule). Aturan yang mungkin dan sesuai dengan basis pengetahuan dari 8 variabel input dan 1 variabel output berjumlah 413 rule, diantaranya sebagai berikut :

1. IF (Warna is Sangat Jernih) AND (Kekeruhan is sedikit) AND (TDS is baik) AND (Nitrit is rendah) AND (Nitrat is rendah) AND (Coliform is tidak ada) AND (E-Coli is tidak ada) AND ( $\mathrm{pH}$ is asam) THEN (Hasil is air dapat diminum)

2. IF (Warna is Sangat Jernih) AND (Kekeruhan is sedikit) AND (TDS is baik) AND (Nitrit is rendah) AND (Nitrat is rendah) AND (Coliform is tidak ada) AND (E-Coli is tidak ada) AND ( $\mathrm{pH}$ is asam) THEN (Hasil is air bersih)

3. IF (Warna is Sangat Jernih) AND (Kekeruhan is sedikit) AND (TDS is baik) AND (Nitrit is rendah) AND (Nitrat is rendah) AND (Coliform is tidak ada) AND (E-Coli is tidak ada) AND ( $\mathrm{pH}$ is basa) THEN (Hasil is air dapat diminum)

4. IF (Warna is Sangat Jernih) AND (Kekeruhan is sedikit) AND (TDS is baik) AND (Nitrit is rendah) AND (Nitrat is rendah) AND (Coliform is tidak ada) AND (E-Coli is tidak ada) AND ( $\mathrm{pH}$ is basa) THEN (Hasil is air bersih)

5. IF (Warna is Sangat Jernih) AND (Kekeruhan is sedikit) AND (TDS is baik) AND (Nitrit is rendah) AND (Nitrat is rendah) AND (Coliform is tidak ada) AND (E-Coli is tidak ada) AND ( $\mathrm{pH}$ is netral) THEN (Hasil is air dapat diminum). 


\subsection{Aplikasi Fungsi Implikasi}

Misalkan data yang digunakan adalah data pertama pada lampiran 1 yaitu nilai Warna $=4$, Kekeruhan $=0$, TDS $=1$, Nitrit $=0,31$, Nitrat $=1,75$, Coliform $=0$, e-coli $=0$, dan $\mathrm{pH}=$ 7,07, maka nilai keanggotaan dari setiap variabel input sebagai berikut :

- Warna

a) Himpunan Fuzzy Sangat Jernih $\mu_{\text {warna sangat jernih }}=1$

- Kekeruhan

a) Himpunan Fuzzy Sedikit $\mu_{\text {kekeruhan sedikit }}=1$

- TDS

a) Himpunan Fuzzy Baik

$$
\mu_{T D S \text { baik }}=1
$$

- Nitrit

a) Himpunan Fuzzy Rendah

$$
\mu_{\text {nitrit rendah }}=1
$$

- Nitrat

a) Himpunan Fuzzy Rendah

$$
\mu_{\text {nitrat rendah }}=1
$$

- Coliform

a) Himpunan Fuzzy Tidak ada

$$
\mu_{\text {coliform tidak ada }}=1
$$

- e-coli

a) Himpunan Fuzzy Tidak ada

$$
\mu_{e-\text { coli tidak ada }}=1
$$

- $\mathrm{pH}$
a) Himpunan Fuzzy netral $\mu_{p H \text { netral }}\left(\frac{8,5-7,07}{1,5}\right)=0,953$
b) Himpunan Fuzzy basa
$\mu_{\text {pH basa }}\left(\frac{7,07-7}{1,5}\right)=0,0467$

Langkah selanjutnya, menentukan nilai keanggotaan dari rule-rule yang berlaku menggunakan metode Minimum ( $\alpha-c u t$ ). Rule yang terpengaruh nilai keanggotaannya adalah aturan 3, aturan 4 dan aturan 5, dengan nilai masing-masing adalah $\alpha_{3}=0467, \alpha_{4}=0.0467$ dan $\alpha_{5}=$ 0,953 . Nilai-nilai tersebut digunakan untuk mendapatkan derajat kebenaran setiap himpunan output fuzzy. Adapun derajat kebenarannya menggunakan metode Max (maksimum) sebagai berikut:

Derajat kebenaran himpunan air dapat diminum

$$
\begin{aligned}
& =\max \left(\alpha_{3}, \alpha_{5}\right) \\
& =\max (0.046,0.953) \\
& =0.953 \\
& =\max \left(\alpha_{4}\right) \\
& =\max (0.0467) \\
& =0,0467
\end{aligned}
$$


Setelah derajat kebenaran dari himpunan output diketahui, maka diperoleh gambar gabungan himpunan output. Gambar terbagi menjadi 5 bidang yaitu Z1, Z2, Z3, Z4 dan Z5 yaitu :

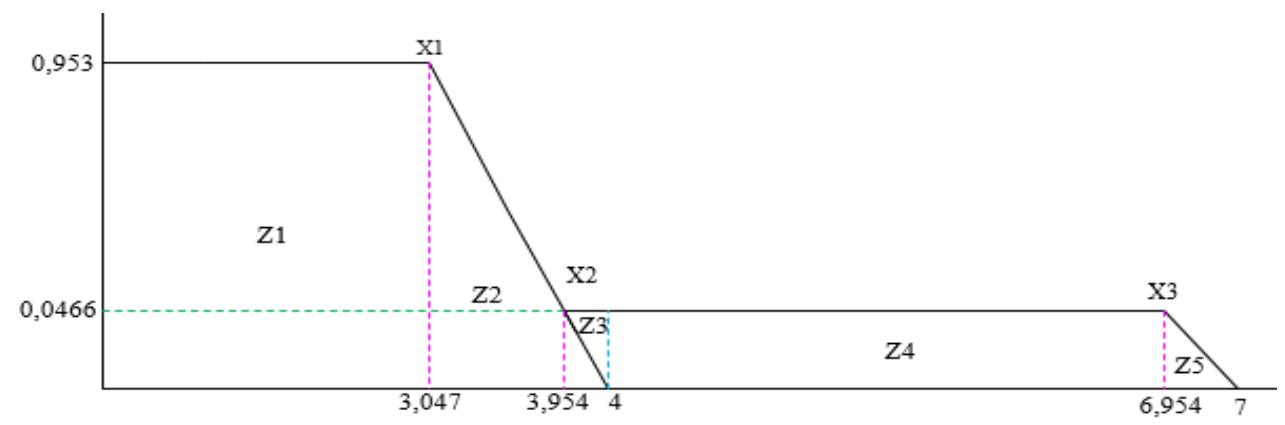

Gambar 10 : Daerah Hasil Inferensi Variabel Output Hasil

\subsection{Penegasan (defuzzyfikasi)}

Proses defuzzyfikasi dilakukan dengan menggunakan metode centroid. Daerah hasil inferensi variabel output akan dihitung masing-masing momen dan luasnya.

Bagian pertama (Z1)

$$
\begin{aligned}
M_{1} & =\int_{0}^{3,047} 0,953 x d x \\
& =4,4239 \\
L_{1} & =3,047 \times 0,953 \\
& =2,903791
\end{aligned}
$$

Bagian kedua (Z2)

$$
\begin{aligned}
M_{2} & =\int_{3,047}^{4} \frac{4-x}{1} x d x \\
& =1,5279102 \\
L_{2} & =\frac{1}{2} \times(4-3,047) \times 0,953 \\
& =0,4541045
\end{aligned}
$$

Bagian ketiga (Z3)

$$
M_{3}=\int_{3,954}^{4} \frac{4-x}{1} x d x
$$

$$
\begin{aligned}
=0,004199 \\
L_{3}=\frac{1}{2} \times(4-3,954) \times 0,0466 \\
=0,001058
\end{aligned}
$$

Bagian keempat (Z4)

$$
\begin{aligned}
M_{4} & =\int_{4}^{6,954} 0,0466 x d x \\
& =0,7539 \\
L_{4} & =(6,954-4) \times 0,0466 \\
& =0,13765
\end{aligned}
$$

Bagian ketiga (Z5)

$$
\begin{aligned}
M_{5} & =\int_{6,954}^{7} \frac{7-x}{1} x d x \\
& =0,007373 \\
L_{5} & =\frac{1}{2} \times 0,0466 \times 0,0466 \\
& =0,00105
\end{aligned}
$$

Dengan menggunakan metode titik pusat (centroid) nilai hasil adalah sebagai berikut :

$$
\begin{aligned}
d^{*} & =\frac{M_{1}+M_{2}+M_{3}+M_{4}+M_{5}}{L_{1}+L_{2}+L_{3}+L_{4}+L_{5}} \\
& =\frac{4,4239+1,527+0,004+0,7539+0,007373}{2,903791+0,4541045+0,001058+0,13765+0,001058} \\
& =\frac{6,611}{3,497} \\
& =1,89
\end{aligned}
$$

Jadi, apabila nilai output sebesar 1,89 maka dapat diambil keputusan bahwa air tersebut berada di himpunan fuzzy air dapat diminum. 


\subsection{Desain Sistem}

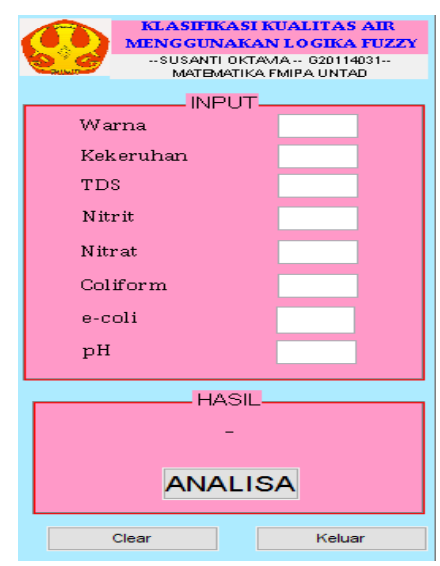

Gambar 11 : Tampilan Sistem

\subsection{Hasil Analisis dan Uji Coba}

Pengujian dilakukan terhadap 72 data hasil uji laboratorium, 36 data bersumber dari PDAM Uwe Lino Kab. Donggala dan 36 data bersumber dari PDAM Kota Palu. Pengujian dilakukan dengan cara membandingkan output yang dihasilkan oleh sistem terhadap hasil aktual yang diperoleh dari PDAM. Berdasarkan hasil pengujian maka diperoleh tingkat keakurasian sebagai berikut :

Keakurasian sistem $=\frac{\text { Jumlah hasil yang sesuai terget }}{\text { jumlah data }} \times 100 \%=\frac{68}{72} \times 100 \%=94,44 \%$

\subsection{Pembahasan}

Dalam penelitian ini menghasilkan sebuah sistem yang mampu mengambil keputusan dalam menentukan kualitas air. Untuk dapat mengambil keputusan dalam menentukan tingkat kualitas air, data hasil uji laboratorium dari parameter kualitas air yakni warna, kekeruhan, TDS (Total Dissolved Solid), pH, nitrat, nitrit, e-coli dan coliform yang telah di input oleh user akan di proses secara otomatis di dalam sistem menggunakan inferensi fuzzy mamdani. Selanjutnya, akan muncul pada layar kategori kualitas air berupa kualitas air dapat diminum, air bersih atau air tercemar.

Dari pengerjaan secara manual pada salah satu data yang tersedia yaitu nilai Warna $=$ 4 , Kekeruhan $=0$, TDS $=1$, Nitrit $=0,31$, Nitrat $=1,75$, Coliform $=0$, e-coli $=0$, dan $p H=$ 7.07 maka hasil yang diperoleh menyatakan kualitas air dapat diminum dengan nilai numerik adalah 1,89. Hal tersebut sama dengan hasil keluaran pada sistem yakni 1,89 yang menyatakan air dapat diminum pula. Hal ini menunjukkan bahwa proses yang bekerja pada sistem berjalan dengan baik dan sesuai dengan yang diharapkan. 


\section{KESIMPULAN}

Berdasarkan hasil penelitian, dapat disimpulkan bahwa sistem inferensi fuzzy dapat digunakan untuk mengambil keputusan dalam menentukan kualitas air PDAM. Hal ini dapat dibuktikan dari data uji yang bersumber dari PDAM Uwe Lino Kabupaten Donggala dan PDAM Kota Palu diperoleh tingkat keakurasian sebesar $94,44 \%$ yakni 68 data sesuai target dan 4 data berbeda dengan target yang diharapkan.

\section{DAFTAR PUSTAKA}

[1] Priyanto, Dwi, Peran Air dalam Penyebaran Penyakit, Volume 07 No 01, 2011.

[2] Kusumadewi, S, Aplikasi Logika Fuzzy untuk pendukung keputusan, Graha IImu, 2002, Yogyakarta.

[3] Peraturan Menteri Kesehatan Republik Indonesia No. 492/MENKES/PER/IV/2010 tentang Persyaratan Kualitas Air Minum.

[4] Peraturan Menteri Kesehatan Republik Indonesia No. 416/MENKES/PER/IX/1990 tentang Persyaratan Kualitas Air Minum.

[5] World Health Organization, Total Dissolved Solids in Drinking-water, Geneva 27, 2003, Switzeland 